Motrivivência Ano XXI, No 32/33, P. 126-155 Jun-Dez./2009

\title{
OLIMPÍADA 2016 - O \\ DESENVOLVIMENTO DO \\ SUBDESENVOLVIMENTO
}

Nilso Ouriques

\begin{abstract}
Resumo Abstract
A olimpíada de 2016 no Rio de Janeiro, é um momento histórico das políticas públicas de esporte e lazer no Brasil. Depois do Estado passar por várias fases em sua longa história dessas políticas, chegamos a um momento diferenciado, onde um governo populista aprofunda as diretrizes neoliberais no esporte. Este momento que une sociedade, Estado e economia, consegue um consenso indiscutível e redefine a estratégia de desenvolvimento do esporte, no sentido do esporte de rendimento. Ser desenvolvido no esporte, significa agora conseguir uma ótima colocação

no ranking de 2016. assim, se esquecem as políticas direcionadas ao esporte educacional e participação e se

The Olympic Games 2016 in Rio de Janeiro, is a historic moment of public policy for sport and leisure in Brazil. After the State pass through several stages in its long history of these policies, we arrive at a different time, where a populist government deepened the neoliberal policies in the sport. This moment that unites society, government and economy, achieve a consensus indisputable and redefines its strategy to develop the sport within the meaning of sport performance. Be developed in the sport now means getting a great position in the ranking of 2016. well, forget the politics directed to sports and
\end{abstract}

1 Mestre em Sociologia Política e Professor do Centro de Ciências da Saúde, da Universidade para o desenvolvimento do Oeste de Santa Catarina - UNOESC - Joaçaba/SC.

Contato: nilso.ouriques@unoesc.edu.br 
Ano XXI, $n^{\circ} 32 / 33$, junho e dezembro/2009

mascara a realidade com o esporte de rendimento. Enquanto todos falam em um novo desenvolvimento do esporte no Brasil, indicamos que este momento

é marcado pelo desenvolvimento do subdesenvolvimento do esporte nacional, sendo nossas diretrizes cooptadas e comandadas pelo esporte espetáculo. Palavras-chave: Olimpíada, desenvolvimento, subdesenvolvimento

\section{As relações entre a política, economia e sociedade}

O desafio que me foi colocado estabelecia a necessidade de uma análise acerca das relações entre os Jogos Olímpicos de 2016 no Rio de Janeiro e seus aspectos econômicos. Forçado a pensar essa temática, deparei-me com inúmeras possibilidades associativas que nos levariam a uma compreensão mais acurada do processo pelo qual passaremos nos próximos anos, até chegarmos à grande festa olímpica.

Como não consigo entender os aspectos econômicos dissociados dos políticos, creio que é preciso primeiro remeter nosso pensamento sobre a dualidade economia e política. Na visão clássica das ciências sociais, economia e política são elementos essenciais de uma determinada sociedade, as duas faces de uma educational participation and masks the reality with the sport of income. While everyone talks about a new development of sport in Brazil, indicate that this moment is marked by the development of underdevelopment of the national sport, and our guidelines co-opted and controlled by the sports spectacle.

Keywords: Olympics.

Development, underdevelopment.

mesma moeda. A dualidade dialética entre infraestrutura e superestrutura se estabelece, observadas pela presença forte do Estado. Assim, sem muito esforço, já lançamos o nosso olhar e atenção, sob três aspectos, que se inter- relacionam.

A sociedade organiza-se para a produção e apropriação de bens e decorre daí as formas diferenciadas desta ou daquela sociedade como também da organização do Estado. A sociedade, marcada pela trama das relações sociais entre classes com interesses diferenciados, deveria ser entendida de acordo com os interesses econômicos a serem disputados por esses grupamentos. A política expressa através das disputas partidárias e materializada no controle do Estado é a expressão do conflito entre esses interesses econômicos e da dominação de uma determinada classe sobre a outra. 
A esta visão clássica da fisiologia social denominou-se, durante algum tempo, de reducionismo econômico, ao mesmo tempo que se determinava que tal visão seria insuficiente para explicar a sociedade como um todo. Na verdade, a interação entre essas esferas, seria a chave mestra para resolver o problema. Mas para compreendermos a relação entre economia, sociedade e política é preciso associar esses elementos a sua história e a um determinado país, no caso, o Brasil.

Historicamente, a sociedade brasileira é uma formação social conservadora que ao controlar o processo produtivo e, portanto, a economia, estabeleceu relações sociais em que o processo de dominação estava sujeito ao controle externo e interno das elites. A burguesia nacional, atendendo aos interesses externos, sujeita a população a um intenso processo de exploração econômica e dominação política. Para tanto, o controle do Estado é o mecanismo através do qual se efetiva a luta política pela hegemonia do processo. A esse tipo de capitalismo, Florestan Fernandes, ${ }^{2}$ chamou de capitalismo dependente, ao qual estão sujeitos a América Latina e o Brasil.
Ao longo de nossa história, os setores subalternos da sociedade brasileira compreenderam a importância de buscar um processo organizativo longo e demorado, através de associações, sindicatos e partidos políticos, com o intuito de romper com este processo de dominação e exploração contumaz. Foram longos anos de luta contra a força política e econômica da burguesia nacional e internacional no controle dos destinos do país. Nesse período, o Estado travestiu-se de várias formas, mas sempre esteve controlado pelos interesses das elites. A história do Brasil que poderia ser resumida em extensos períodos de ditadura com curtas experiências democráticas, acalentou durante todas essas vivências, um longo e progressivo processo de acúmulo de forças dos segmentos subalternos.

A última ditadura que o povo brasileiro enfrentou e aprendeu derrotar durou 21 anos. Esgotadas as suas forças em 1985, o controle político das elites transfigura-se no nascimento da chamada "Nova República" 3 muito bem descrita por Florestan Fernandes.

Essa nova situação política trouxe consigo o crescimento de um Partido forjado nas lutas de base do

2 FERNANDES, Florestan, Capitalismo dependente e Classes Sociais na América Latina. Rio de Janeiro, Zahar, 1973.

3 FERNANDES, Florestan, Nova República?, 3º Ed. Rio de Janeiro, Jorge Zahar, 1986 
Ano XXI, n 32/33, junho e dezembro/2009

sindicalismo paulista, o Partido dos Trabalhadores. A extensa luta desse partido pela consolidação da democracia, ampliação dos espaços e das organizações democráticas e pelo controle do aparelho de Estado foi ganhando espaço nas pequenas e médias prefeituras, alçou voos para governos de Estado e finalmente encontrou condições de disputar a presidência da república. A manutenção da democracia, das lutas e das disputas eleitorais colocou o PT em condições de vencer eleições e controlar a máquina estatal. Esse processo amadurece e ganhou corpo nas mãos de Luis Inácio Lula da Silva, o Lula. Depois de concorrer várias vezes à presidência da República e ser derrotado pelos candidatos da elite brasileira, Lula e o Partido dos Trabalhadores associados a uma grande massa de organizações sociais e outros partidos, compondo um amplo campo das esquerdas, ascendem ao poder.

Com o controle da máquina estatal e com amplo apoio da sociedade, restava a esses setores controlar uma grande economia na América Latina, que Ihe depositavam grandes esperanças. Evidentemente, que o controle sob o Estado em um regime democrático com amplo apoio social, não implica necessariamente na conquista da hegemonia política. São elementos importantes mas não encerram um processo de luta política entre as classes em questão, tanto nas suas relações internas como externas. Essa é só uma parte do enfrentamento político, com desdobramentos imprevisíveis e que dependem essencialmente da correlação de forças entre esses segmentos.

Essa é uma rápida história, que procura de maneira muito superficial relacionar, economia, política e sociedade. Através dela chegamos à sociedade brasileira contemporânea sob o controle do Partido dos TrabaIhadores e seus aliados.

\section{Ostado às políticas Públicas e o Esporte no Brasil}

Como vimos as inter relações entre Estado, sociedade e economia são fundamentais dentro do processo de luta política pela hegemonia. O Estado é extremamente importante, pois é através de sua estrutura, recursos e ação política que atende às demandas da sociedade e assim constrói uma sociedade mais justa ou completamente desigual. Sob o comando da elite brasileira, o Estado configurou-se como um instrumento através do qual a burguesia filtrava os interesses econômicos e políticos, na busca pelo controle absoluto da sociedade brasileira e ganhos de capital.

A relação do Estado com a sociedade acontece através das 
políticas públicas por este desenvolvida nas mais diversas áreas sociais, seja, na educação, transporte, moradia, saúde esporte e outros segmentos. Ao longo da história, essas políticas assumiram uma conotação democrática ou autoritária, de acordo com o perfil do Estado, demonstrado pela presença das forças políticas que o controlavam e pelo momento vivido pela sociedade brasileira.

O Esporte e o lazer fazem parte desse escopo de políticas a serem administradas pelo Estado, no sentido de contemplar as expectativas sociais. Essas políticas assumiram, ao longo da história brasileira, diversas faces. No início do século $\mathrm{XX}$, nos principais centros urbanos do país, o Estado era o elemento financiador das estruturas esportivas. Foi assim no Rio de Janeiro no desenvolvimento do hipismo e do remo, como relatou Victor A. Melo. ${ }^{4}$ Esses esportes consagrados ao lazer das elites encontraram o desenvolvimento estrutural através da mão do Estado, nas suas relações aproximativas com a elite carioca. De mero elemento financiador das estruturas, a partir do período Vargas, o Estado passa a ser um instrumento de controle, administração e vigilância da atividade esportiva ${ }^{5}$. A legislação lançada por Getúlio em 1941 trás todo o entendimento do esporte e do lazer como instrumento de dominação de classe, utilizado pelo governo para inflar os seus objetivos políticos e ideológicos. Na década de 70, sob pesada ditadura militar, o esporte enquanto aparelho ideológico do Estado, cumpriu o Papel de disseminar pelo mundo a idéia de um país pujante e plenamente democrático, espelhado na conquista do tri campeonato mundial e na projeção de sua maior estrela, o atleta do século, Pelé, como exemplo dessa democracia racial.

Depois desse período, o Estado, no Brasil, passa por inúmeras transformações na sua forma de ser e agir, lançando sob o esporte uma nova matriz ideológica capaz de alterar-lhe os seus rumos. O Estado brasileiro do período neoliberal dos governos de Fernando Collor de Mello e Fernando Henrique Cardoso encontrará, nos ídolos esportivos nacionais, o seu mecanismo de aproximação política entre Estado e sociedade. É dessa forma que se iniciam transformações profundas na vida esportiva nacional, primeiro com Bernard e depois com Zico no controle das políticas públicas

\footnotetext{
4 MELO Victor Andrade. A cidade Esportiva, Primórdios do esporte no Rio de Janeiro. Rio de Janeiro, Relume Dumará, 2001.

5 MANHÃES Eduardo Dias, Políticas de esporte no Brasil, $3^{\circ}$ Ed. Rio de Janeiro, Paz e Terra, 2002.
} 
Ano XXI, n 32/33, junho e dezembro/2009

de esporte e lazer. Este inicia um processo de abertura do esporte para o mercado, balizado pela lei que leva o seu nome. Já no governo de Fernando Henrique Cardoso, o esporte ficará sob o comando de Edson Arantes do Nascimento, o Pelé, que reformula a legislação anterior, criando a lei Pelé. Essa lei representa, principalmente para o futebol, a total abertura do mercado nacional para o exterior, a possibilidade de comercialização dos clubes através da venda de seus departamentos de futebol para a iniciativa privada, o fim da lei do passe e inúmeras outras mudanças dentro dos princípios neoliberais imperantes.

Enquanto estes encaminhamentos reforçam as idéias do neoliberalismo no esporte, a luta social altera a correlação de forças na sociedade brasileira e impulsiona o movimento e a organização popular para dar apoio as forças populares, capitalizadas pelo Partido dos Trabalhadores, que depois de concorrer a presidência da República por três vezes, com Luis Inácio da Silva, vence as eleições e coloca no poder, pela primeira vez na história desse país, um operário no comando do Estado. O PT e as forças que o ajudaram a chegar ao poder, iniciam assim, uma nova fase de controle sob o aparelho de Estado e, portanto, sob as políticas públicas, que a partir de agora levam a sua marca ideológica e a história de militância do partido.

Dessa forma, era de se esperar que as políticas públicas de esporte e lazer fossem administradas por setores que comandaram a reformulação e revitalização, assim como a nova direção ideológica a partir do processo de democratização da sociedade brasileira depois de 1985. Historicamente, essas forças estiveram alojadas, no campo da educação física, dentro do Colégio Brasileiro de Ciências do Esporte, o CBCE. Depois de criado um Grupo de trabalho temático com os seus principais intelectuais, a produção acerca das políticas públicas no esporte e lazer nacional iniciou, um processo de investigação científica sobre os caminhos seguidos por essas políticas por todo país. Esses segmentos normalmente encontravam, sob os seus quadros, intelectuais do PT, segmentos ligados a administração pública do esporte e lazer de prefeituras ou governos do Estado em todo país.

O próprio partido dos Trabalhadores criou um setorial ligado às políticas de esporte e lazer que alimentava os debates internos e as linhas de atuação nas administrações desse partido. Assim, podemos afirmar que o acúmulo existente nas políticas públicas de esporte e lazer do CBCE e do setorial do PT dava a estes setores um amplo campo de 
experiências capazes de dinamizar e alterar, de uma vez por todas, a diretriz impressa no esporte e lazer pelos setores conservadores em toda a longa história da relação entre Estado e a sociedade brasileira.

Muito embora houvesse esse acumulo, curiosamente os avanços não se faziam hegemônicos na estrutura partidária. Historicamente os partidos de esquerda sempre tiveram pouco interesse, além de manifestar uma imensa dificuldade para lidar com as políticas de esporte e lazer. Alimentava-se, na esquerda, o preconceito, que o esporte sempre fora um elemento de alienação e instrumento de dominação política da direita. A medida que as forças de esquerda assumiram prefeituras e governos de Estado, no seu extenso caminho até a vitória à presidência da república, as secretarias de esporte eram normalmente discriminadas e ocupadas pelos menores partidos, como um elemento sem grande valor social e representatividade política. Não se cobrava desses segmentos um novo planejamento ou reviravoltas ideológicas nas políticas a serem adotadas, eram simplesmente cargos que compensavam a participação no processo político. Em muitos locais desse país, o PC do B já havia assumido essas pastas e havia ganho alguma experiência, sem no entanto possuir qualquer discussão acumu- lado sobre o assunto. É dessa forma que as públicas de esporte e lazer e suas respectivas estruturas, foram colocadas pelo governo Lula, nas mãos de segmentos pouco afeitos a este debate e passaram assim a ser comandadas pelo Partido Comunista do Brasil nas mãos de seus dois maiores representantes: Agnelo Queiroz(2003-2006) e Orlando Silva a partir de 2006.

Passados mais de sete anos, essas políticas públicas não foram marcadas por uma visão administrativa que as diferenciassem dos períodos anteriores e também não demonstraram quase que nenhuma transformação política ou ideológica marcante, que merecesse ser considerada como elemento capaz de representar o acúmulo vivido no CBCE e no setorial do PT. Ao contrário do que se poderia esperar, alguns autores afirmam existir hoje um aprofundamento das políticas neoliberais no esporte do período anterior.

Essa visão está associada a uma diretriz ideológica assumida pelas políticas públicas de esporte vinculadas ao governo Lula, que entendem como foco de seus programas a população mais pobre desse país. A população seria acionada a participar de "projetos sociais" com base em ações de organizações intituladas do "terceiro Setor". A garantia dos direito sociais da população seria agora conquistada através do 
Ano XXI, n 32/33, junho e dezembro/2009

desenvolvimento de campanhas onde se busca resgatar a responsabilidade social da sociedade e dos empresários, contando inclusive com a ação de voluntários.

A difusão do termo "projeto social" para referir-se a essas políticas públicas, insere-se na dinâmica política dos grupos dominantes, de desfazer os direitos e transformá-los em mercadorias negociáveis como uma característica neoliberal. Os projetos sociais são implementados por organismos da sociedade civil públicos (municipais ou estaduais) ou privados (ONGs, associações de moradores, movimentos sociais) e correm o risco permanente de extinção. O exemplo característico desses programas é o projeto do governo federal "segundo tempo".

Para os setores alinhados ao campo crítico da educação física, como Lino Castellani Filho ${ }^{6}$, o que ocorreu com as políticas públicas foram três processos: a) um imenso avanço dos setores conservadores do campo esportivo devido a explícita e concreta terceirização das políticas pelo PT, b) um aprisionamento dos setores que aplicam a política pública pelos setores conservadores, que majoritários e hegemônicos, trabalham a construção do imaginário popular sobre o assunto e c) uma busca constante pela legitimação que leva à execução de políticas públicas que caminham no sentido de contemplar as expectativas dos setores conversadores do campo esportivo, uma verdadeira capitulação, ao que o autor chama de "síndrome de Estocolmo". A síndrome é definida como um estado psicológico desenvolvido por pessoas vitimas de sequestro, onde a vítima procura se identificar como captor ou conquistar simpatia do sequestrador. Ou seja, os setores do PC do B procuraram se identificar e buscar simpatia dos setores mais conservadores e reacionários do campo esportivo nacional e acabaram ficando prisioneiros deles, dos donos do poder, dos senhores dos anéis. Nessas condições, as possibilidades de rever as políticas públicas de esporte e lazer, são praticamente nulas.

Por outro lado, a professora Celi Zulke Taffarel professora da FACED/UFBA em seu texto "como iludir o povo com o esporte para o público", avalia a situação de uma maneira um pouco diferente. Afirma ser impossível analisar os caminhos do esporte sem uma rápida descrição do que é o governo Lula, já que este possui uma fachada ideológica de "centro esquerda" mas trabalha no desenvolvimento de políticas neoliberais. Segundo a autora,: " $\mathrm{O}$

6 Disponível em :<http:/www.observatóriodoesporte.org.br >. Acesso em :20 jun 2010. 
modo petista de governar incorporou todas as coisas contra as quais a esquerda brasileira lutou nesses últimos anos: aparelhamento da máquina, enganação, desqualificação, silenciamento, isolamento e eliminação dos divergentes, ataque e destruição de quadros históricos das lutas no campo e na cidade; cooptação, nepotismo corrupção, clientelismo, populismo." ${ }^{\prime 7}$

Para Celi o governo Lula atentou para gestos simbólicos na área de esporte e lazer que contentariam as reivindicações populares. Tais gestos estariam presentes na instalação do Ministério do Esporte, na realização das Conferências Nacionais, na delimitação da Política Nacional de Esporte e Lazer e na configuração do Sistema Nacional de Esporte e Lazer. Estes gestos simbólicos estariam muito longe de configurar uma política cultural de interesse de uma nação soberana e não são decorrentes da posição política do governo de atender, com determinação, as reivindicações históricas na área do esporte e lazer, representando, antes medidas compensatórias para aliviar a pobreza com segurança e continuar privilegiando os interesses das elites brasileiras e internacionais que assim se valem dos recursos públicos para seus benefícios. Conclui afirmando acerca do esporte e lazer no governo Lula: "Nossa hipótese é de que estão sendo configuradas novas forças, que na aparência são de "centro esquerda", mas que na essência de suas construções históricas podem culminar em novas forças de direita ou reforçar a velha e carcomida elite e seus valores burgueses ${ }^{\prime \prime}$

\section{Os donos dos anéis e as mãos que embalam o berço}

A realização dos Jogos Olímpicos, em qualquer país do mundo, impõe a associação de vários interesses econômicos, políticos e sociais. Nesse emaranhado de interesses, projetam-se, como soberanos ou hegemônicos, aqueles situados no núcleo duro do poder locado no Comitê Olímpico Internacional, nas 35 federações esportivas internacionais e 205 comitês olímpicos nacionais e nas suas estratégias corporativas de caráter supranacional, que reunidas em uma única organização, recebeu o nome de "club". Associados a essas organizações esportivas estão as grandes multinacionais dos 
Ano XXI, n 32/33, junho e dezembro/2009

materiais esportivos, a mídia e seus interesses nos mercados, tanto os já consolidados como aqueles ainda por serem abertos.

Em meio a essa situação, o Brasil, e mais especificamente o Rio de Janeiro, iniciou uma longa luta para a realização dessa competição. Ao final desse processo, Luis Inácio Lula da Silva em outubro de 2009, fez em Copenhague, na Dinamarca, um longo discurso em defesa da candidatura do Rio de Janeiro como sede das Olimpíadas de 2016. O chefe do Estado brasileiro afirmou que a identidade do Brasil uniria todos os continentes, sendo os jogos uma oportunidade sem igual para o Brasil e que essa era uma candidatura de toda a América do Sul. Suas palavras foram fortalecidas pelo presidente da FIFA João Havelange que disse esperar completar os seus cem anos no Rio de Janeiro em 2016. O presidente do Comitê Olímpico Brasileiro, Carlos Arthur Nuzman eternizado na presidência da entidade, também usou da palavra, alertando o Comitê Olímpico Internacional que a escolha da cidade certa é uma aposta da entidade no futuro. Logo depois, falou o presidente do Banco Central, Henrique Meirelles que avalizou esse cheque, salientando a boa saúde financeira do país, sendo seguido pelo governador do Rio de Janeiro Sérgio Cabral Filho, que afirmou o novo momento de segurança desfrutado pelo Estado. Estava lançada a sorte de um país que buscava a realização dos Jogos como um elemento capaz de unir todos os segmentos da sociedade brasileira e latino americano. O Estado brasileiro lançava uma proposta que uniria toda uma nação e fomentaria a economia nacional.

Ao final, o Rio de Janeiro conquistou o direito de sediar os jogos Olímpicos de 2016. O placar foi folgado. A vitória arrasadora. O poder econômico de Chicago, a eficiência de Tóquio e a história de Madri ficaram para trás. Na terceira e última rodada de votação, sobraram o Rio de Janeiro e Madri, com a vitória do Rio por 66 votos contra 32. A imprensa brasileira e a internacional salientaram elementos que justificaram a conquista e dentre eles à participação do presidente Lula, assim como o grande momento vivido pela economia brasileira, o fantástico boom das exportações nos preços dos commodites e os investimentos nas políticas sociais, com uma previsão do PIB para 2010 de $5.7 \%$, refletindo assim a condição do Brasil como um país que se encontra entre as nações de liderança política mundial e inserindo o "continente esquecido" no mapa político internacional. Essas avaliações se somam àquelas que salientam a importância das descobertas de petróleo e a crescente influência do país no diálogo 
internacional, algo que projetou Lula como o personagem do ano de 2009 no mundo.

Lula e seu governo possuem parte muito importante no processo assim como também o Comitê Olímpico Brasileiro. Para Nuzman, presidente do COB, a vitória é a conseqüência de uma longa estratégia que contou com a ajuda do presidente de honra do COI, Juan Antonio Samaranch, que já há algum tempo teria indicado o caminho a ser seguido pelo Brasil. A estratégia era simples: primeiro era preciso realizar os Jogos Pan Americanos de 2007 e sonhar com a Olimpíada de 2012, para finalmente realizar a de 2016. Mesmo a derrota de 2012, configurava-se como uma jogada estratégica assim como também realizar com sucesso os Pan Americanos. A luta para trazer os mega eventos para o Brasil associa portanto duas estratégias nacionais. Primeiro o desejo populista do governo Lula, através do PC do $B$, de fazer do esporte uma estratégia de projeção nacional e internacional do país, ou seja, um Brasil que seja visto como democrático, potência econômica em projeção e agora potência esportiva; segundo, a manifestação política internacional do Comitê Olímpico Brasileiro, através de Carlos Nuzmann de lutar pela ampliação do seu espaço político dentro do COI que se associa aos in- teresses econômicos e políticos do movimento olímpico internacional, comandados pelo COI e seu club. Assim, podemos afirmar que há três mãos embalando o berço: $O$ Estado brasileiro, o COB com seus interesses políticos internacionais e o $\mathrm{COI}$ e sua organização corporativa.

Os donos dos anéis representam assim o resultado de todo processo organizativo do esporte em nível internacional, associado aos interesses econômicos da indústria do esporte mundial. A movimentação do esporte pelo mundo atende, portanto, aos interesses econômicos e políticos desses segmentos por novos e promissores mercados, que com um olhar imperialista, observam os Estados nacionais lutarem pela conquista do direito à realização dos Jogos Olímpicos. Quem comanda a indústria do espetáculo esportivo pelo mundo é portanto a industria do esporte, coordenado por seu braço político supranacional, as organizações esportivas. Ao comandar o seu famoso e disputado calendário esportivo acenam aos Estados nacionais e burguesias locais para seus ganhos, tanto políticos como econômicos. Para os Estados nacionais essa é uma oportunidade ideológica e política ímpar de unificar a nação em torno dos mesmos ideais esportivos e de amor à pátria e a seus valores morais. Para isso precisa fomentar a atividade esportiva, 
Ano XXI, n 32/33, junho e dezembro/2009

cumprindo um imenso caderno de obrigações para que possa justificar esse desejo pela sede dos jogos e, se assim o faz, justificar esse desejo apontando para a necessidade de desenvolvimento esportivo de seu país, assim como pelas novas oportunidades no campo do turismo e dos benefícios econômicos advindos desses espetáculos.

Essa é a fórmula geral adotada pelo Estado nacional ao longo da história. O que o diferencia de país para país é a importância dada ao esporte e lazer enquanto elemento cultural presente nas políticas públicas e o grau de desenvolvimento incorporado por essas forças na sociedade da qual faz parte. No Brasil, a oportunidade de realizar esse evento, guarda toda uma discussão pormenorizada, que para ser apropriada com sabedoria, deveria buscar na sua história e nas políticas públicas adotadas até o presente momento um instante de reflexão sobre o nosso processo de "desenvolvimento esportivo". Este debate teria como foco o papel do Estado, da sociedade e da economia como elementos propulsores da atividade esportiva.

O anúncio do Rio de Janeiro como sede dos Jogos de 2016 de- sencadeou as mais variadas ondas de comentários desarticulados, carentes de história e solidez teórica capaz de apontar para alguma direção confiável. A sociedade brasileira, perplexa diante do anúncio e da euforia que tomou conta do Rio de Janeiro, tornou-se solidária ao movimento e apoiou a causa antes perdida, emocionou-se com ela e a espera com ansiedade. A imprensa noticiou no inicio o fato com euforia, rompendo parcialmente com o "complexo de vira lata". Nelson Rodrigues explicou essa sua criação da seguinte forma: "por complexo de vira lata, entendo eu a inferioridade em que o brasileiro se coloca voluntariamente, em face do resto do mundo"g e continuando afirmaria: " o brasileiro é um narciso as avessas, que cospe na própria imagem. Eis a verdade: não encontramos pretextos pessoais ou históricos para auto-estima"10.

Digo que rompeu parcialmente, pois de maneira contínua e duvidosa retratava os feitos das outras cidades que sediaram os jogos com êxito para salientar as dificuldades que seriam encontradas no Brasil, embalando estas dificuldades nos milhões que seriam gastos para a recuperação da cidade, seu processo

9 RODRIGUES, Nelson, Flor de Obsessão: as 1000 melhores frases de Nelson Rodrigues. Rio de Janeiro, Companhia das Letras, 1992. 
de reurbanização, problemas estruturais e sociais, eram dificuldades em cima de dificuldades, todos embalados por um moralismo que questionava ser isso certo ou errado, diante de outros tantos problemas por que passa o país. A burguesia carioca explodiu de felicidade com as novas possibilidades econômicas calcada em lucros fabulosos e na possibilidade de uma nova cidade para se viver. O Estado, não perdeu sua raiz ideológica e lançou a sua diretriz para os próximos anos: "Brasil potência olímpica para 2016". Dessa forma simples, sociedade, economia e Estado encontraram-se para falar do mesmo assunto, sob prismas diferentes.

Em meio a esse emaranhado de novas idéias ressurge a preocupação com o desenvolvimento esportivo, agora sob a forma de discurso ideológico do Estado, colocando o Brasil como potência olímpica. O "desenvolvimento esportivo", algo esquecido e pouco trabalhado do ponto de vista estrutural e de planejamento, passa a ser a justificativa ideológica para que se viabilizem imensos gastos na área. O desenvolvimento esportivo não encontra, hoje no Brasil, uma definição conceitual aproximada.
No imediatismo dos debates, a imprensa e o senso comum apegam-se para definir esse desenvolvimento a posição a que o país está colocado no ranking dos jogos. Partilhando dessa associação infantil nossos dirigentes esportivos do $\mathrm{COB}$ informam à grande imprensa e assim à população nacional que o Brasil, passará a ser uma potencia esportiva e que para tanto, precisamos saltar do $22^{\circ}$ colação no ranking para a $10^{\circ}$ colocação. Se alguém procurava alguma definição mais plena de validade científica encontra agora, nas palavras do ministro do esporte do país, a decisão que precisava para sanar as dúvidas conceituais acerca do que é desenvolvimento esportivo. A posição no ranking,irá nos transformar em potencia esportiva, para tanto precisamos gastar milhões de dólares em inúmeras transformações estruturais na cidade do Rio de Janeiro assim como na base estrutural de esportes. Tudo isso será feito em seis anos.

\section{"Sim, nós podemos"11}

A campanha da candidatura do Rio de Janeiro custou 140 milhões de reais e foi comandada por três consultores internacionais,

11 Expressão utilizada pelo Presidente Barak Obama durante a sua campanha presidencial e reeditada pelo presidente Lula para designar a capacidade brasileira de fazer os Jogos Olímpicos de 2016. 
Ano XXI, n 32/33, junho e dezembro/2009

especialmente contratados: Mike Lee, que trabalhou na campanha vitoriosa de Londres 2012, Michael Payne, que durante vinte anos foi encarregado do marketing do COI e o americano Scott Givens, responsável pelo sucesso do Super Bowl, a espetacular final do campeonato de futebol americano nos EUA. Depois da consagração. Lula parafraseou Barak Obama, afirmando as potencialidades do Brasil e do Rio de Janeiro e da capacidade de alavancar a economia e transformar a cidade. Agora o Rio de Janeiro terá de vencer o desgoverno e o abandono, criadas nos últimos anos por uma elite arcaica e políticas públicas desastrosas. Precisa superar a violência,a favelização e a poluição de suas lagoas. Os números apresentados na imprensa nacional assustam, serão mais de 1.500 turistas e 15 mil atletas que visitaram 34 instalações esportivas novas e que atingirá ao final, um público de 4,4 bilhões de pessoas no planeta durante os dezesseis dias do encontro.

Para alguns, trata-se na verdade de uma tarefa nacional para recuperar a cidade maravilhosa. Essa recuperação deverá materializar-se na forma de investimentos que somam quase 29 bilhões de reais, sendo que desses 23,5 bilhões são em infraestrutura. Observe alguns desses números: R\$ 17,5 milhões serão gastos na construção de um novo píer na área do forte de Copacabana e arquibancada temporária com 5 mil lugares. $\mathrm{R} \$ 19$ milhões na construção de um estádio de vôlei de praia com arquibancada temporária com capacidade para 12 mil pessoas, $\mathrm{R} \$ 34,6$ milhões na construção da arquibancada temporária com 5 mil lugares para a prova de Maratona, revitalização da marina e construção de arquibancada temporária para $10 \mathrm{mil}$ pessoas, R\$ 75 milhões serão gastos construção de um estádio aquático olímpico, na Barra da Tijuca, com duas piscinas e capacidade para 18 mil pessoas, $\mathrm{R} \$ 4,5$ milhões serão utilizados na reforma do estádio de remo e construção de arquibancada provisória com 10 mil lugares.

Por sua vez, as principais intervenções urbanas se dar-se-ão na expansão do metrô que inclui a ampliação de Ipanema, Gávea, Barra da Tijuca além da integração com o Maracanã e a compra de trens em um total de 2,9 bilhões. A construção das linhas BRT (Bus Rapid Transit) ligando a Barra da Tijuca à zona Oeste e à Zona norte da cidade envolverá o volume financeiro no valor de 1,6 bilhões. A reforma do aeroporto internacional Tom Jobim impõe a quantia de 946 milhões, aumentando a sua capacidade de 9 mil passageiros para 15 mil, a ampliação do aeroporto 
Santos Dumont custará 45 milhões para realizar a ampliação de $3 \mathrm{mil}$ passageiros para 5 mil. Outra obra de suma importância é a construção do arco metropolitano, uma via de $145 \mathrm{Km}$ que ira desafogar o trânsito nos acessos à cidade no valor de 930 milhões. No campo do urbanismo, prevê-se a execução da obra de revitalização da zona portuária, com criação de área de lazer, habitação e negócios inspirada em Buenos Aires e Barcelona no valor de 3,2 bilhões. A experiência internacional revela a intenção de dotar a região de tudo o que uma cidade moderna deve oferecer num mesmo espaço, ou seja,: comércio, residências, turismo e atividades culturais. Prédios comerciais e residenciaisincluindo habitações de interesse social- serão erguidas ao lado das futuras atrações, como uma pinacoteca, um museu e um aquário. A preocupação com a melhoria nas favelas, inclui a construção de infra estrutura em cinco favelas no valor de 1 bilhão. O meio ambiente será atingido com a despoluição da Lagoa Rodrigo de Freitas, Baia da Guanabara e Lagoas de Jacarepagua no valor de 1 bilhão.

$\mathrm{O}$ que se pode concluir da situação, é que uma cidade com imensos problemas urbanos e sociais, encontrou, no esporte, ou melhor, no evento esportivo internacional, a capacidade de redefinir o seu projeto estratégico. Dezesseis dias de competição foram o suficiente para unir os interesses econômicos, a ação do Estado e a força da opinião pública. Da mesma forma, redefinem a lógica estatal para o desenvolvimento esportivo nacional, agora para um Brasil que quer ser potência olímpica.

Em meio ao turbiIhão de novidades, emergem duas propostas para o Brasil potência Olímpica. Uma a ser formulada pelo $\mathrm{COB}$ e suas associadas, às federações esportivas e outra pelo governo federal, que segundo Ricardo Leyser, principal executivo da pasta estaria sendo inspirada no instituto de excelência do esporte da Austrália, ou ainda em modelos como os de Cuba, EUA e Alemanha.

\section{"Subdesenvolvimento não se improvisa. É obra de séculos". 12}

O esporte possui uma capacidade, acima da média de falsificar o real. Jogadores normais, em períodos de escassez de craques tornam-se monstros sagrados com um ou dois gols e alguma ajuda da

12 RODRIGUES, Nelson, Flor de Obsessão, as 1000 melhores frases de Nelson Rodrigues. Rio de Janeiro, Companhia das Letras, 1992. 
Ano XXI, n 32/33, junho e dezembro/2009

imprensa, equipes sufocadas por crises econômicas falsificam a sua realidade erguendo um simples troféu. Sociedades marcadas pelas ditaduras, torturas e mortes, esquecem suas dores e sua história diante da TV e dos espetáculos esportivos. É por isso que Nelson Rodrigues escreveu: "Em futebol, o pior cego é o que só a vê a bola". ${ }^{13}$

A Copa do Mundo de 2014 e os Jogos Olímpicos de 2016 cumprem assim um papel ideológico profundo, o da cegueira no campo das políticas públicas. Num passe de mágica, dois eventos esportivos, somam-se a um propósito populista e a ganância econômica para decretar, quase que de imediato, a existência de um novo tempo onde o subdesenvolvimento esportivo seria algo do passado. Esse subdesenvolvimento esportivo mascarado ideologicamente de "mal desempenho", foi constatado pela imprensa, pelo COB e pelo próprio Estado ao analisar a posição assumida pelo Brasil no Ranking esportivo mundial, expresso no resultado dos consecutivos Jogos Olímpicos. Em Atlanta (1996) fo-

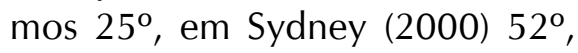
em Atenas (2004) $16^{\circ}$ e em Bejing (2008) $22^{\circ}$ colocado. Para esses analistas, nosso melhor resultado foi em Atenas, o que possibilitaria com o auxilio de ajudas estruturais, programas especiais e algumas estratégias federativas a possibilidade de saltarmos para, no mínimo a $10^{\circ}$ posição. Colocados entre as dez maiores países no quadro de medalhas, seremos uma potência esportiva.

Essa análise infantil recebeu uma recente contestação do IPEA- Instituto de Pesquisa Econômica Aplicada, que através do estudo de número 1394: "Avaliação da eficiência técnica dos países nos Jogos Olímpicos de Pequim 2008" e coordenado pelo professor Alexandre Marinho, ${ }^{14}$ coloca para o campo da educação física uma nova forma de medir o desenvolvimento esportivo. O estudo analisou o desempenho dos países ganhadores de medalhas nas Olimpíadas de Pequim em 2008. Ao invés de expressar o desempenho, ou desenvolvimento esportivo apenas em termos de conquistas de medalhas, a "eficiência" relativa dos países foi avaliada por meio da utilização da metodologia conhecida como Análise Envoltória de Dados- Data Envelopment Analysis (DEA). Assim utilizou-se uma fronteira de eficiência para o conjunto dos países, cotejando os 
resultados obtidos com os recursos disponíveis em cada país. Os resultados (outputs) serão diferentes combinações de medalhas conquistadas - ouro, prata e bronze- e os recursos (inputs) serão o PIB, US\$ PPP; a população de cada país e a esperança de vida ao nascer.

De acordo com os estudos, a $22^{\circ}$ posição no ranking do $\mathrm{COI}$, falsifica uma realidade ainda maior do subdesenvolvimento. Em um primeiro modelo de análise, quando são consideradas as medaIhas de ouro, o escore brasileiro de eficiência foi de 14,23\% fazendo o país situar-se na $47^{\circ}$ posição em um grupo de 55 países analisados. No segundo modelo, que utiliza as medalhas discriminadas por tipo, o país atingiu um escore de 30,9\% de eficiência, ocupando a posição de $55^{\circ}$ posição em um ranking de 87 países. No terceiro modelo, com o total de medalhas somadas, o escore de eficiência baixa para 22,56\% levando o país a $51^{\circ}$ posição em um grupo de 87 países.

Segundo o IPEA, mais que uma posição nada satisfatória, o país para se colocar entre os mais eficientes, ou seja, ir para a fronteira da eficiência, necessita de nada menos do que quadruplicar o número de medalhas em relação ao efeti- vamente conquistado nas últimas olimpíadas. Para o IPEA, os países "grandes" em termos de população e de PIB ocupam as primeiras posições, pois a produção de medalhas esta otimizada, correspondendo portanto, aos elevados níveis de recursos disponíveis. Em tese, a única forma de crescer no mundo olímpico e tecnicamente eficiente seria ter uma grande população ou um grande PIB. Assim o estudo se posiciona a respeito da posição assumido pelo país em Pequim:

Aliada à magnitude do PIB e ao tamanho da população, o Brasil conta ainda, com mais um fator que contrasta com o resultado não muito bom nas Olimpíadas de Pequim. Foi justamente nesses jogos que o país investiu e direcionou mais verbas ao esporte em participações olímpicas. Além disso, estima-se que, adicionado aos repasses governamentais e à lei de incentivo ao esporte, o Comitê Olímpico contou com aproximadamente, o dobro da verba recebida pela Lei Piva com relação à primeira edição dos jogos beneficiados por essa fonte de financiamento. ${ }^{15}$

O objetivo do estudo resume-se na tentativa de propor um 
Ano XXI, n 32/33, junho e dezembro/2009

ranking alternativo ao "oficial" gerado exclusivamente pelo número de medalhas que privilegia os países "grandes" praticamente os únicos capazes de obter maiores quantidades de medalhas. Assim, se Países como EUA e a China demonstram a sua imensa capacidade, países, por outro lado com pequeno PIB e população reduzida, mas que atingem resultados relevantes em termos de medalhas, seriam considerados eficientes como a Jamaica, a Mongólia e o Zimbábue.

Ao terminar o estudo, o IPEA constata que é difícil precisar o porquê da falta de sucesso brasileiro, mas que diante da análise da população e do PIB o país está muito bem dotado, mas que isto somente não basta. Dessa forma o IPEA, sem afirmar, sugere para uma avaliação da situação que devem ser analisadas as variáveis esportivas, ou seja, sua política esportiva. No que se refere às condições mínimas necessárias para um bom desempenho, o país desfruta de bom potencial. Ao instituto não caberia uma análise da política esportiva do país, mas aponta para o nó do problema.

Colocadas as duas situações nas quais se propõem a avaliar o desenvolvimento esportivo nacional, tanto a do Ministério do Esporte/COB, quanto a do IPEA que partem de pressupostos teórico metodológicos completamente diferentes, chegamos a seguinte constatação: o Ministério do Esporte e o $\mathrm{COB}$, solucionam a questão com a estratégia desenvolvimentista de um Brasil "potência Olímpica" . Para Lula e seu ministério, a posição no ranking internacional colocaria o Brasil na condição de um país desenvolvido no esporte e não mais na condição de não desenvolvido ou subdesenvolvido. A expressão subdesenvolvido é por mim colocada, pois em qualquer debate ela faz o contraponto com a palavra desenvolvido, exaustivamente utilizada. O movimento olímpico internacional não faz essa analogia entre países desenvolvidos ou subdesenvolvidos no esporte, pois isto remeteria a discussão para o campo da economia e da política, situação essa que não interessaria aos senhores dos anéis que historicamente o tem remetido ao plano da neutralidade. Para esses senhores, só existe a necessidade permanente da superação olímpica que segue a linha ascendente da busca de medalhas e troféus.

Teríamos assim o desenvolvimento pelo desenvolvimento, como uma sequencia linear a ser buscada pelos países. A posição no ranking é apenas um número, que oscila de acordo com inúmeras variáveis que não são facilmente diagnosticáveis. Elementos como sorte, esforço, dedicação ou mesmo 
o aparecimento de um fenômeno esportivo que possa conquistar seis ou sete medalhas de ouro em determinada modalidade, seriam capazes de fazer a posição no ranking sofrer um grande viés. É por isso, que o COB e o Ministério dos Esportes insistem em afirmar para toda a imprensa nacional que o "nosso melhor resultado" é a $16^{\circ}$ posição e que a solução para o problema é chegar em $10^{\circ}$ lugar custe o que custar. $O$ espantoso é que tanto o COB como o Ministério concordam com a tese. Ao COB, que faz parte da instituição olímpica e que portanto defende os seus interesses e valores, é compreensível aceitar esse conceito de desenvolvimento esportivo, pois isto é intrínsico a sua lógica funcional, ao seu modus operandi, é o sistema defendendo aquilo que o próprio sistema criou. A classificação no ranking é um conceito de desenvolvimento esportivo criado pelo $\mathrm{COI}$ e quase que de maneira natural, é aceito como válido. Mas aos Estados nacionais, o conceito não é colocado como obrigatório, muito pelo contrário, é questionado. Os países possuem modelos, concepções ideológicas e políticas diferentes de esporte e podem, muito facilmente, não abraçar essa proposta.

O interessante e espantoso, no caso brasileiro, é que a realização das Olimpíadas de 2016 no Rio de
Janeiro já determinou a necessidade do projeto "potência Olímpica" tanto pelo COB como pelo Ministério, aceitando-se o conceito de desenvolvimento esportivo espelhado no resultado. Agora a estratégia de desenvolvimento do esporte brasileiro para os próximos seis anos é o evento e o resultado. Todos os esforços e os recursos financeiros do governo do PT e das forças de esquerdas foram absorvidas ideologicamente para esta proposta desenvolvimentista. Assim, se em 2016, chegarmos em $10^{\circ}$ lugar, podemos nos dizer uma potência olímpica e portanto, ou por analogia, um país desenvolvido no esporte.

Para o IPEA, afeito as análises econômicas, essa condição já deveria ser uma realidade, devido aos elementos econômicos salientados. Dessa forma, não seria a base econômica e social a responsável pela situação em que o país se encontra, mas a política esportiva. O IPEA constatou a nossa falta de eficiência esportiva em conquistar medalhas e troféus tendo em vista a situação econômica e social do pais, mas os caminhos a serem seguidos para superar essa situação é um problema da política esportiva a ser adotada.

O caminho a ser seguido pelo governo Lula, a que Celi Taffarel designa de centro esquerda com tendências a fortalecimento 
Ano XXI, n 32/33, junho e dezembro/2009

das políticas neoliberais, aponta para o caminho da intensa e rápida especialização esportiva, através da conjugação de esforços das federações esportivas e do COB, tendo o Estado como base de sustentação econômica. Assim, centros de treinamentos especializados, desenvolvimento de laboratórios, alta tecnologia, ampliação da rede de captação de talentos esportivos e o financiamento em massa do esporte de rendimento são alguns dos caminhos a serem seguidos pela política nacional de desenvolvimento esportivo. Resultados rápidos e racionalmente planejados para alcançar tal situação. Assim, gastaremos todos os nossos esforços e recursos em uma proposta ideológica de esporte nada inovadora, mas que reafirma os valores e a moral capitalista do esporte internacional. O Estado de "centro esquerda" endossa e aprofunda na prática a política neoliberal trazendo esta política para o solo nacional, agora com o apoio da sociedade, do Estado e da economia.

A chegada do grande espetáculo esportivo ao Brasil é mais intensa e mais profunda do que simplesmente a participação neles. Antes a periferia ia visitar o centro do desenvolvimento esportivo de uma maneira despreocupada, agora, foi absorvida pelo centro e irá obedecer às diretrizes. Ir aos jogos é diferente de fazê-los, pois não existe o envol- vimento econômico e político e a sobrecarga ideológica e emocional que se reproduz dia após dia e que altera, de maneira súbita, o desenvolvimento de um planejamento esportivo sério, capaz de levar a superação do subdesenvolvimento.

A sociedade brasileira que já aprovou e deseja entusiasticamente o espetáculo esportivo no Brasil, será envolvida cada vez mais pela mídia na cobrança pela execução de uma grande festa, sem falhas e ao mesmo tempo em uma grande participação brasileira, a melhor de todas seja lá de que forma for. Esse desejo social que irá se manifestar de maneira intensa e hegemônica, como necessidade de afirmação da auto estima brasileira, como símbolo de nacionalidade e força de um povo e um país, irá se unificar e projetar o esporte de rendimento como necessidade básica do Estado brasileiro. A sociedade do espetáculo esportivo que chegou ao Brasil consumirá a Copa do Mundo e as Olimpíadas da mesma forma como bebe Coca Cola e come McDonald's em todas as faixas etárias em qualquer parte deste país, com uma intensidade antes nunca vista. Essa é uma diferença ideológica não analisada pelos especialistas, na definição dos próximos seis anos de política esportiva brasileira assim como o seu "legado cultural", na dinâmica do desenvolvimento do espetáculo esportivo. 
Em todo o mundo, o esporte virou uma linguagem universal que pela televisão é captada e potencializada através de ondas cada vez mais crescentes de propaganda, que associam o esporte a outras mercadorias dessas multinacionais do entretenimento que atingem pobres e ricos da mesma forma e com a mesma intensidade. Mesmo sistemas culturalmente mais resistentes como a antiga URSS, as ruas de Moscou e a praça vermelha em 1990, abriram-se para a Coca Cola e para a vitória do ocidente, simbolizando algo forte como a queda do muro de Berlim. O grau de sedução da mercadoria esporte e seus sócios maiores não encontram obstáculos pelo mundo, faz parte da mesma uniformização e da busca da rentabilidade cultural estendida a todos. Uma produção em série, em grande escala que impõe o consumo e a adequação às regras por estes setores ditadas.

A sociedade do espetáculo esportivo colocou países como: China, Afeganistão, EUA, Cuba, Austrália, Zimbábue, República Dominicana e Brasil em uma mesma competição. São povos, histórias, economias e culturas diferentes e fá-las competir nos mais variados esportes, para chegar a um resultado final, chamado de ranking onde, em uma escala hierárquica, será determinado quem é mais ou menos desenvolvido. Os resultados consagram, na sua grande maioria, os países ricos em detrimento dos pobres, apontando para a ideia de seu maior nível de desenvolvimento esportivo. Esta escala mundial faz com que países como o Brasil, obedecendo a essa diretriz ideológica entendam ser essa uma verdade absoluta e fazem dela uma política de Estado. O Brasil olímpico ficou agora prisioneiro desta idéia, com o apoio da sociedade e com o desejo da economia. O espetáculo esportivo é esta união estável que substitui o planejamento esportivo estrutural e os vínculos deste com o compromisso com as ideias do esporte enquanto cidadania e qualidade de vida para a grande maioria da população, vinculados com os campos do esporte educacional e de participação. A sociedade do espetáculo e o espetáculo esportivo anestesia esta diretriz em nome do esporte de rendimento e de uma visão distorcida de desenvolvimento esportivo

Ao abarcar o esporte rendimento como foi feito pelo governo Lula, o esporte nacional que já possuía vínculos fracos com a cidadania e com qualidade de vida para a população, com o esporte entendido enquanto direito social, assim como o é saúde e educação, redefiniu a estratégia, acoplada 
Ano XXI, n 32/33, junho e dezembro/2009

aos interesses internacionais do grande espetáculo esportivo. Capitulou de maneira definitiva, agora com amplo apoio da população, da economia e alavancado pelo Estado. A partir deste momento, a elite dirigente do esporte nacional formada pelas federações esportivas e confederações, pelo COB, no caso das olimpíadas, os clubes brasileiros de futebol da série $\mathrm{A}$ e a CBF no caso da Copa do Mundo, todos os setores, de importância política crucial para o esporte nacional, associados a Mídia e aos interesses dos grupos econômicos que serão beneficiados pelos dois espetáculos esportivos, constituemse como sócios minoritários da grande empresa internacional que comanda o espetáculo esportivo. Mas, do ponto de vista interno, potencializam-se como verdadeiros interlocutores do desenvolvimento esportivo nacional, capacitam-se como elite dirigente hegemônica para requisitar os benefícios econômicos e ditar as diretrizes políticas, numa aproximação clara com o poder do Estado e no assalto a estrutura econômica.

Ao Estado nacional compete o papel de locomotiva econômica dessa empresa a viabilizar toda a infraestrutura dos dois espetáculos, que embora distantes um do outro, não estão separados da proposta ideológica e do planejamento do Estado no plano da intensa motivação nacional. Ao primeiro, está reservada o papel de uma mobilização nacional que irá remexer com as estruturas do futebol nacional, atualizando-o historicamente ${ }^{16}$, dotando-o de uma estética e plasticidade européia, potencializando o nacionalismo e o patriotismo para expectativas acima da média com a qual estamos acostumados nesses momentos de grande euforia. Ao segundo, reserva-se uma ação concentrada, local e regional, agindo sobre grupos específicos, mas com desdobramentos midiáticos da mesma envergadura que o anterior, muito embora sem a mesma intensidade emocional.

Ao final desse processo, o Estado associado aos interesses econômicos dos parceiros internacionais, atualizaram as estruturas esportivas do futebol nacional, dotaram o Rio de Janeiro da melhor estrutura olímpica que o país já possuiu, com gastos econômicos nunca antes feitos de maneira tão

16 Atualização histórica é um conceito utilizado por Darcy Ribeiro, para demonstrar o processo de colonização cultural sofrido pela sociedade brasileira depois de contínuos encontros civilizatórios com a cultura européia. Encontrado em : " O Povo Brasileiro- A formação e o sentido do Brasil 2 ed. São Paulo: Companhia das letras, 1996. 
rápida e concentrada e com tantos dividendos políticos e ideológicos. A nova condição modernizante, muito embora possa causar euforia nos representantes do esporte de rendimento, aprofunda, por sua vez, a dialética da dependência ${ }^{17}$ esportiva, que fica cada vez mais prisioneira do esporte rendimento, do espetáculo esportivo e do lazer passivo das grandes massas da população, tudo isto feito sem resistência e pelo contrário, com o aval da população. Todo o movimento, não significa e não deve necessariamente estar associado por ingenuidade a progresso, ou a idéia do desenvolvimento esportivo endógeno, mas há uma concepção deste vinculada a elite do esporte no mundo e no Brasil que só consolida o atraso nacional. A era do esporte espetáculo chegou e consolidou-se.

Assim, o esporte e o lazer no Brasil chegam à maturidade no estágio mais avançado onde se transforma em espetáculo e passam a ser comercializados, criando-se como mercadorias a assumir no mercado brasileiro a possibilidade de elemento motriz do falso desenvolvimento esportivo, um desenvolvimento para fora, oco, fugaz, sem valor estrutural e organizativo que um desenvolvimento planejado teria. Atividades produzidas para cumprir um papel estanque de lazer passivo e de esporte espetáculo, nada mais.

Este movimento não é isolado, vem acompanhado de um caráter de domínio ideológico de ponta, ao afirmar-se, devido aos resultados esportivos projetados e esperados para 2016, como um dos mais organizados do mundo e o mais desenvolvido da América do Sul, quase um sub imperialismo, ${ }^{18}$ ao mesmo tempo em que potencializa o caminho do evento esportivo interno e assalta o Estado. A comercialização do evento, de que se reveste o espetáculo esportivo, comprova os objetivos da busca do lucro, comandado por organizadores e produtores com os olhos fixos na rentabilidade econômica. Reforça-se assim o seu caráter de mercadoria e de disseminador dessa ideologia esportiva.

Sempre é bom lembrar que Jean Marie Brohm, ${ }^{19}$ conceituando o esporte como aparelho ideológico das relações sociais capitalistas, afirma-o como instrumento capaz

17 Dialética da dependência conceito trazido por Ruy Mauro Marini,para expressar a relação desigual entre os países centrais e periféricos no capitalismo. Encontrado em: Dialética da Dependência. $10^{\circ}$ Ed. México: Era, 1993.

18 Sub Imperalismo expressa utilizada por Ruy Mauro Marini, para expressar a posição política e econômica do Brasil na América Latina.

19 BROHM, Jean Marie, Materiales de Sociologia Del Deporte. Madrid: La Piqueta,1993. 
Ano XXI, n 32/33, junho e dezembro/2009

de desenvolver elementos como: hierarquia, obediência, subserviência, defende a ideia de uma organização baseada na competição e no recorde e propaga em grande escala as idéias do super-homem, da ascensão social, sucesso, eficiência e do individualismo.

Dessa forma, a cultura corporal que se tornou esportiva, utilizando-se de critérios como rendimento financeiro e os resultados esportivos vê o crescimento do esporte no Brasil refletido nos eventos esportivos. Estados como São Paulo, Rio de Janeiro e Santa Catarina, pulverizaram a política esportiva de seus estados através do desenvolvimento intenso e fragmentado do evento esportivo, por onde são sugadas todas as verbas públicas. Essa nova fase do esporte nacional, já é uma realidade que teve seu caminho ideológico construído pela entrada do mundo empresarial nesses negócios e pelos seus discursos modernizantes acerca dos métodos administrativos (Adidas, Nike, FiFa e COI) recheadas de sucesso empresarial a render elogios ao esporte espetáculo e a sua comercialização nos moldes de um capitalismo avançado.

Em a sociedade do espetáculo Guy Debord (1967) afirma
:" Toda vida nas quais reinam as condições de produção se anuncia como uma imensa acumulação de espetáculos. Tudo o que era diretamente vivido se afastou numa representação" 20 Para o autor, a sociedade capitalista que vive esse momento histórico prefere a imagem e a representação ao realismo concreto, adora a aparência e se distancia do ser, prefere a ilusão à realidade a imobilidade à atividade, ou seja, as pessoas abdicam da dura realidade para viver um mundo de aparências e pelo consumo permanente de fatos, notícias, produtos e mercadorias. Isso ocorre pela mediação das imagens e mensagens dos meios de comunicação de massa que são a manifestação superficial mais esmagadora da sociedade do espetáculo.

Os eventos esportivos aproximam-se com uma imensa facilidade da constatação de Guy Debord. O evento é o espetáculo, ou seja, uma forma de manipulação em que os indivíduos são obrigados a contemplar e a consumir passivamente as imagens de tudo o que lhe falta na existência, num processo contínuo de empobrecimento, submissão e negação da vida real. Esse consumo propiciado pela sociedade brasileira e seus dirigentes implica

20 DEBORD Guy, A sociedade do espetáculo- Comentários sobre a sociedade do espetáculo, Rio de Janeiro, contraponto, 1998 . 
numa sensação de felicidade, grandiosidade e ousadia. A sociedade brasileira relaciona-se pelo espetáculo, que é uma relação social.

Par Guy Debord, o espetáculo constitui-se na realidade e a realidade no espetáculo, não existindo limites para as coisas. O homem passa a viver uma vida sonhada e idealizada, na qual a ficção mistura-se à realidade e vice versa. $\mathrm{O}$ espetáculo vivenciado e analisado pelo autor encontra, no evento esportivo brasileiro, e nesse caso, nas Olimpíadas de 2016, o seu reflexo. A realidade do subdesenvolvimento esportivo brasileiro marcada pela falta de planejamento, autoritarismo das políticas públicas, falta de transparência administrativa, desfinanciamento da infraestrutura, corrupção da elite dirigente, encontra agora, no espetáculo esportivo e nos eventos, a capa maquiadora. A superprodução dessas mercadorias em marcas variáveis induz e garante um poder de liderança nacional e agora no continente sul americano, fazendo com que os indivíduos vivam em um mundo falso. O critério de validade da realidade está sendo falsificado, gerando desinformação na sociedade acerca da realidade brasileira no plano esportivo. A desinformação, como mau uso da verdade esportiva, faz desaparecer os critérios de verdade e validade, criando um mundo de desinforma- ção, baseado no espetáculo, no consumo, na fragmentação da realidade e da verdade, um real fabricado que não é real.

O Brasil sempre analisou e viveu o grande espetáculo esportivo, olhando-os de longe, como algo feito por outras sociedades na qual éramos apenas convidados a participar, meros observadores da cultura e do desenvolvimento esportivo destes países e das excentricidades alheias. Agora, na condição de país sede, seremos atingidos por outros elementos determinantes, tanto externos como internos, que não foram necessariamente dimensionados antes de sua efetivação. Em meio a embriagues, a euforia e o devaneio constatado tanto na sociedade como na elite dirigente do esporte nacional, ofusca-se a visualização da realidade esportiva brasileira assim como os resultados que podem brotar desse processo para o desenvolvimento esportivo nacional.

Em meio a grande explosão do espetáculo esportivo no Brasil, a utilização que faço da expressão :"O subdesenvolvimento não se improvisa. É obra de séculos" retrata a necessidade de refletir sobre um país que não se conhece no esporte e que resiste a idéia de receber esta denominação. Esse grande continente, marcado pelas desigualdades sociais e econômicas determina um desenvolvimento desigual que concentra ilhas de desenvolvimento esportivo de um 
Ano XXI, n 32/33, junho e dezembro/2009

lado e bolsões de miséria do outro. A realidade manifesta-se no esporte nos diferentes níveis de políticas públicas traçadas e executadas por todo país. Enquanto o sul e o sudeste possuem níveis de desenvolvimento consideráveis, o restante do país desconhece ou simplesmente engatinha nestas políticas. Mesmo no sul e no sudeste do país, onde as estruturas estatais são bem desenvolvidas e já possuem alguma história acumulada e onde estão as políticas públicas mais avançadas, aspectos como a centralização das políticas, a não democratização e a falta de transparência na utilização dos recursos são claras e inequívocas marcas deste subdesenvolvimento. Nessas duas regiões estão acumuladas as maiores marcas e recordes nacionais, a maior quantidade de atletas e as maiores fontes de financiamento esportivo principalmente as públicas e depois as pequenas experiências privadas. Nesse cenário de desenvolvimento desigual e recobrado por fraturas temporais difíceis de serem superadas, o subdesenvolvimento é algo real que não será superado pela melhor posição do Brasil no ranking internacional.

Todos sabem que as políticas públicas federais, somente recentemente conseguiram iniciar um processo de tentativa de unificação, através da criação do Ministério do esporte, das Conferências Nacionais e estaduais de esporte e lazer e da criação do Sistema Nacional de Esporte. São encaminhamentos políticos recentes e de resultados duvidosos e sem tempo de consolidação. Sem a consolidação destas políticas, e a ampliação e aprofundamento das políticas de esporte participação e educacional com amplo envolvimento da sociedade, não se estenderá cidadania e qualidade de vida através do esporte, para a grande maioria da população brasileira. O verdadeiro desenvolvimento esportivo deve centrar-se e preocupar-se em levar o esporte e o lazer à população brasileira, como instrumento de vivência de novas e criativas experiências corporais, culturais, históricas e organizativas da população. O esporte e lazer, como fonte e necessidade de emancipação cultural da população, como forma de suplantar o subdesenvolvimento, através do qual se possa ter uma nova leitura de sua vida e do mundo. Quando o esporte e o lazer são negados à população brasileira instala-se sim, um processo de desenvolvimento do subdesenvolvimento ${ }^{21}$, que faz

21 Expressão utilizada por Ruy Mauro Marini, para demonstrar a única possibilidade econômica e política possível para os países periféricos dentro do desenvolvimento do capitalismo internacional. 
com que o esporte deixe de ser uma perspectiva de vida empírica, vivida, trabalhada no dia a dia da população, para transformar-se em um instrumento ficcional, implantado na tela de uma televisão. Deixa de ser realidade, para ser ilusão, sonho, devaneio e se aproxima assim de um instrumento ideológico de dominação de que o espetáculo esportivo é a sua maior criação.

Assim, o subdesenvolvimento esportivo não está presente e retratado na posição assumida pelo Brasil no quadro geral de medalhas do COI e das olimpíadas como querem nos levar a crer a elite dirigente esportiva nacional através do Ministério dos Esportes, das entidades de administração esportiva e do COB, mas na negação permanente de estruturas físicas esportivas e de lazer para a grande maioria da população brasileira e na negação de uma política pública sólida e permanente que atenda a estes interesses, que historicamente foram negados. Assim como não se pode pensar a educação, sem escolas, professores e tecnologia, que desenvolvam os conteúdos necessários, não se pode pensar o esporte e lazer, sem quadras, ginásios, piscinas, pistas, material esportivo e professores nas comunidades, bairros e vilas deste país, administrando os seus conteúdos, sem a preocupação com medalhas, troféus, índices e campe- ões, mas almejando a construção do homem e da mulher esportiva, cidadã, preocupada com a saúde, desenvolvimento cultural e afetivo através deste mecanismo esportivo. O esporte e o lazer como mecanismo de organização, associação das pessoas em suas comunidades, como vivência organizativa de suas ações e planejamento de sua vida.

O subdesenvolvimento esportivo é a negação deste direito ao esporte e lazer na comunidade, com a participação de todos, e que historicamente nunca se constituiu em uma conquista do povo brasileiro. É por isso, que o subdesenvolvimento esportivo não se improvisou no Brasil. Ele foi uma obra de muitos e muitos anos, de negação do povo e do cidadão através do esporte. $\mathrm{O}$ histórico desenvolvimento urbano sem qualquer planejamento que se incorpora as preocupações com esporte e lazer, a ausência de políticas públicas que contemplasse estas expectativas e a voracidade do mercado imobiliário que corroeu com as poucas áreas disponíveis ao esporte e lazer, deixam a população dos bairros e vilas sem qualquer alternativa capaz de dar vazão as suas necessidades. Esta é a realidade das grandes metrópoles e das médias cidades do Brasil. A situação só aparenta alguma melhora quando a vida se desloca para o interior e pequenas cidades, mas daí, muito 
Ano XXI, n 32/33, junho e dezembro/2009

embora, ainda existam espaços sociais amplos para o esporte e lazer, inexistiram as políticas de apoio aos projetos educacionais capazes de dar sustentação às necessidades. Assim o esporte e lazer, que já foi conhecido como comunitário e hoje recebe a denominação de participação, desenvolve um processo profundo de desenvolvimento do seu subdesenvolvimento, da sua negação como direito social a ser garantido pelo Estado.

O exemplo clássico que podemos dar, tendo em vista a ausência de um estudo nacional acerca do assunto, pode ser encontrado em Santa Catarina. O estado que se orgulha da estrutura estatal e planejamento na área de esporte e lazer, encontra-se hoje em situação de penúria, pensa e desenvolve o esporte de rendimento e os eventos esportivos ligados ao esporte espetáculo. Possui uma pequena preocupação com o esporte educacional e escolar, através de competições, que só sobrevivem, pois estão voltadas pára a descoberta de talentos esportivos. A fora isto, desfinanciou por completo a estrutura esportiva do estado inteiro, ou seja, as estruturas esportivas existentes, sejam elas de caráter estadual ou municipal, passam por um profundo processo de destruição, onde não existem reparos ou reformas, estão degradando-se e ao mesmo tempo não há novas construções e nem recursos para elas. Desta forma as estruturas públicas estão, na sua grande maioria, abandonadas e sem políticas para a sua utilização.

Sendo assim, o esporte participação sobrevive das iniciativas isoladas de associações de moradores, centros comunitários, instituições privadas, clubes e associações esportivas e de lazer com pouco apoio das prefeituras e quase nenhum apoio do governo do Estado. $\mathrm{O}$ apoio das prefeituras, depende da sensibilidade política das fundações, comissões ou departamentos municipais de esporte para estas políticas, mas sem qualquer coordenação estadual a ser seguida. Desfinanciado, sem políticas públicas municipais diretas e efetivas e sem uma coordenação estadual, o esporte participação definha a olhos vistos.

Dessa forma, sobram-nos poucas alternativas do que fazer. Se constatamos que houve um pequeno avanço nos últimos anos de caráter organizacional, com o aparecimento do Ministério do esporte, Conferências Nacional e Estaduais e a criação do Sistema Nacional de Desporte, percebemos também que esse movimento que busca dar unidade política no esporte e no lazer é inda muito recente e imaturo, incapaz de dar contornos definitivos as necessidades de uma política nacional de desporto e 
lazer. Percebemos, da mesma forma, que este movimento inicial foi sobrepujado por uma força maior e mais determinante que é a chegada dos grandes eventos esportivos ao país, a Copa do Mundo de 2014 e as Olimpíadas de 2016. O Espetáculo esportivo a partir de agora irá sugar todas as forças, energia e a atenção das elites dirigentes para estes dois momentos importantes da vida esportiva nacional, deslocando o vetor do desenvolvimento esportivo, para o campo do resultado esportivo e assim, para o desenvolvimento de políticas públicas que atendam ao desenvolvimento do desporto de rendimento, em detrimento do esporte participação e educacional. É esta a visão que irá determinar os rumos do esporte nacional nos próximos seis anos, inundando mentes e os corações nacionais, com uma visão de desenvolvimento esportivo, que o associa definitivamente e de maneira ingênua ao resultado esportivo. Tanto na Copa do Mundo como nas Olimpíadas, valorizando um conceito de desenvolvimento olímpico internacional, colonizador e profundamente neoliberal, ao privilegiar os interesses econômicos dos grupos externos ligados ao $\mathrm{COI}$ e as suas multinacionais do esporte, as elites nacionais do esporte nacional, vinculadas as federações, confederações esportivas e COB, assim como os interesses políticos populistas do governo do PT e das forças de "centro esquerda" que iram comandar o país nos próximos anos.

Esta proposta de desenvolvimento esportivo não faz parte da origem histórica do PT e de seus intelectuais, suas bandeiras foram abandonadas e substituídas pela visão oportunista do PC do B que no comando do Estado e associado aos interesses econômicos e políticos das elites esportivas, tanto nacional como internacional, entrega à população brasileira uma proposta sedutora de desenvolvimento esportivo associado ao grande espetáculo esportivo, que potencializado pelos interesses da mídia, constroem uma grande ilusão esportiva e de lazer nacional, ao mesmo tempo em que submetem a população brasileira ao desenvolvimento contínua do seu subdesenvolvimento esportivo, baseado no abandono do esporte e lazer participação e na letargia do esporte educacional. Tudo isto embalado no discurso recorrente de que avançamos, progredimos, quando na verdade andamos para trás.

Assim como não é por uma pessoa estar ocupada que isto se reveste em eficiência, ou a simples idéia do movimento estar associado a progresso, que estes novos cenários implicam rompimento com o subdesenvolvimento esportivo. 
Ano XXI, n 32/33, junho e dezembro/2009

\section{REFERÊNCIAS}

BROHM, Jean Marie. Materiales de Sociologia Del Deporte. Madrid: La Paquita, 1993.

DEBORD, Guy. A sociedade do espetáculo - Comentários sobre a sociedade do espetáculo. Rio de Janeiro: Contraponto,1998.

FERNANDES Floresta. Capitalismo dependente e Classes sociais na América Latina. Rio de Janeiro: Zahar, 1973

FERNANDES Florestan. Nova República? $3^{\circ} \mathrm{ed}$. Rio de Janeiro: Jorge Zahar, 1986.

MARINI, Rui Mauro. Dialética da Dependência, $10^{\circ} \mathrm{ed}$. México: Era, 1993.

MANHÃES, Eduardo Dias. Políticas de esporte no Brasil, $3^{\circ} \mathrm{ed}$. Rio de Janeiro: Paz e Terra,2002. MELO Victor Andrade. A cidade
Esportiva - Primórdios do esporte no Rio de Janeiro. Rio de Janeiro: Relume Dumará, 2003. RIBEIRO, Darcy. O Povo Brasileiro A formação e o sentido do Brasil, 2 ed. São Paulo: Companhia das Letras, 1996.

RODRIGUES, Nelson. Flor de Obsessão, as 1000 melhores frases de Nelson Rodrigues. Rio de Janeiro: Companhia das Letras, 1992.

$<$ http/www. observatoriodoesporte. org.br $>$

$<$ http/www.facel.ufba/rascunhodigital $>$

$<$ http/www.ipea.gov.br >

Recebido: agosto/2010

Aprovado: agosto/2010 